\title{
Reasons Behind Mis/Understanding English Conversational Implicatures by University Learners in Yemen
}

\author{
Haifa Mohammad Nassar* \\ Department of English, Faculty of Education \& Humanities, University of Hajjah, Yemen.
}

\begin{tabular}{llllll}
\hline Received: 15.05 .2021 & • Accepted: 20.06.2021 & • & Published: 30.06.2021 & • Final Version: 30.06.2021
\end{tabular}

\begin{abstract}
English, as a communication tool, plays an extremely significant role in cross-cultural communication. While it is true that language users can mean exactly what they mean in their utterances, it is also true that they can have their utterances mean much more than what they say. Speakers of English speak indirectly, and using conversational implicatures is a way to be indirect. And as sentences often express messages above and beyond their literal meanings, it is not surprising that pragmatic errors are found in language learning process of EFL learners' communication. Therefore, this study aims at investigating the factors beyond misunderstanding or understanding of English conversational implicatures among Yemeni EFL university learners. It follows an empirical analytical-descriptive method consisting of a test and an interview. Randomly, $50 \%$ of the study population was selected as the study sample. They were 62 Yemeni EFL university learners. A multiple-choice discourse completion test ( MCDCT ) and a semi structure interview were used for collecting the study data. The test contained eleven types of conversational implicature The collected data was analyzed quantitatively and qualitatively. The results reveal that different factors caused misinterpretation of conversational implicatures among Yemeni EFL learners. However, the differences in socio-cultural knowledge and indirectness are instrumental in the misunderstanding of conversational contexts in the study. While the familiarity of some conversational implicatures and formulaic pattern of others pose no challenge for the study subjects to interpret some of the test conversational implicatures. The study test conversational implicatures that are formulaic or familiar to the subjects are easy to grasp. Therefore, this study provides some recommendations that are expected to enable EFL university learners to develop their pragmatic competence regarding English conversational implicature and suggests a reconsideration of the existing methodologies on teaching English as a foreign language. Hence, this would ease the concern of EFL students about English conversational implicature, build up their confidence and enhance language learning.
\end{abstract}

Keywords: English conversational implicatures, Speech acts, EFL university learners.

\section{Introduction}

"Austin's theory of speech acts and Grice's theory of speaker's meaning were both meant to provide the foundation for a theory of language, or at least for a theory of linguistic meaning" (Recanati, 2006, p.443).

Austin (1962) formulates the theory of speech acts, which is considered a first major theory in the study of language use and has been subsequently developed by his student ,Searle. Grice (1989) believes that once we focus on the nature and purpose of rational interaction, there may be differences. He suggests that conversation is a typical purpose-built cooperative enterprise, governed by what he calls the Cooperative Principle: "make your conversational contribution such as is required, at the stage at which it occurs, by the accepted purpose or direction of the talk exchange in which you are engaged" (p. 26). Indeed, a theory of language is based on the two above prominent theories that provide an empirical overview about language production and comprehension that assisting to shape effectively the implicature notion. These 
two theories are expected to help to build the relationship of pragmatics comprehension and language production. Providing EFL university learners with this knowledge about Cooperative Principle and Speech Act is supposed to assist to enhance and develop their pragmatic competence and facilitate their learning.

Since the study is primarily concerned with investigating the factors behind mis/understanding English conversational implicatures by Yemeni university learners, it is perhaps vital to throw some light on teaching English and pragmatics in Yemen. Teaching English in Yemeni universities places more emphasis on how to make students acquire the target language. Students are required to learn and memorize what is offered by instructors and what is included in the prescribed textbooks that are prepared for different university courses. The results of Al-Eryani's study (2008), for example, reveal evidence of imbalance of linguistic and pragmatic competence in English among Yemeni undergraduate learners of English as a foreign language (EFL). Their pragmatic behaviour points out lack of adequate understanding of English pragmatic rules. Al-Sanhani (2007) contends that pragmatics "remain[s] marginal in EFL instruction, both in curricula and methods of teaching" (p. 4)

Al-Ghbari (2016) further conducted a study regarding integrating pragmatic competence in teaching English for specific purposes. The research results reveal a low level of pragmatic competence among second-year students from the Faculty of Medicine at Taiz University. This is mainly ascribed to the influence of their first language as they rely on its norms in understanding and producing English.

Therefore, teaching English in Yemen is more inclined towards structure-based principles than those of communicative language teaching where pragmatics is considered to be the main component of it. Taking the importance of pragmatics into consideration, it can be said that a low level of pragmatic awareness leads to pragmatic failure. In this respect, Ghaleb (2003) concludes that "Arab learners of English [including Yemeni university students] do not possess the appropriate pragmatic competence that enables them to use the interrogative form of correction" (p. 220).

Thus, pragmatics has a vital importance, and teachers, curriculum designers, policymakers and decision makers should pay a closer attention to such a notion. It is necessary to develop in students appropriate strategies of comprehension and production of English conversational implicatures and teach them how to communicate cross-culturally. Amaya (2008) proposes that students should be provided "with the necessary tools to make adequate pragmatic decisions in the L2" (p.20). In other words, they should be made aware pragmatically. Hence, this study attempted to fill the gap in the literature by extending research on reasons behind the mis/comprehension of conversational implicature in English by EFL university learners.

\subsection{Theoretical implications of conversational implicature}

Together with Austin and Searle's theory of Speech Acts, Grice's (1975) Cooperative Principle has been one of the most influential models within the field of pragmatics. Over the years, Grice's theory's influence in contemporary pragmatics is still unquestionable today (Mey, 2002).

Brown and Levinson claim that all cultures perform politeness the same way. A position which has been criticized by many researchers (Wierzbicka, 1985; Held, 1989), who have attempted to show the shortcomings of the theory and call for adjustment. While Brown and Levinson suggest that being more direct is being less polite, some languages like Chinese (Yu, 1999), French (Held 1989), and Polish (Wierzbicka, 1985) challenge this equation.

\subsubsection{A theory of speech act}

. According to Austin (1962), speech acts can be recognized with regard to their structure. Whenever there is a direct relationship between the function of a speech act and its structural form, we have a direct speech act. On the other hand, when there is no direct relationship between a structure and a form, the speech act is considered indirect. He (ibid) argues that "to determine what illocutionary act is so performed we must determine in what way we are using the locution" (p.98). This means that what is said (the locutionary act) does not determine the illocutionary act(s) being performed. Thus, we can perform a speech act directly or 

indirectly, by way of performing another speech act. Searle (1979) states that an indirect speech act is one that is "performed by means of another" (p.60). That means that there is an indirect relationship between the form and the function of the utterance. The speaker does not explicitly state the intended meaning behind the utterance. It is the hearer's task to analyze the utterance to understand its meaning and an indirect speech act is a kind of implicature. More importantly, most usages of speech acts are indirect as pointed out by Levinson (1983). The speech act of requesting, for instance, is infrequently performed by means of an imperative in English. Rather, it is done in a roundabout way.

\subsubsection{A theory of conversation}

. Grice $(1975,1989)$ proposes that participants in a communicative exchange are guided by a principle that determines the way in which language is used with maximum efficiency and effect to achieve rational communication. He calls this principle as the Cooperative Principle, which states that "make your conversational contribution such as is required, at the stage at which it occurs, by the accepted purpose or direction of the talk exchange in which you are engaged." This principle is an umbrella term for nine components that guide how we communicate. These nine components are grouped together into four categories or maxims of conversation including: the maxim of quality (truthfulness), the maxim of quantity (informativeness), the maxim of relation (relevance), and the maxim of manner (perspicuity). According to Grice, the notion of conversational implicature needs that a speaker's meaning to be calculated on the basis of sentence meaning, and presumptions constructed on the speaker's commitment to the four general maxims of the cooperative principle which s/he mainly observes, and expects others to observe and work the meaning out in conversation. The four general maxims are as follows:

The Maxim of Quality: do not say what you believe to be false and do not say for which you lack adequate evidence; the Maxim of Quantity: make your contribution as informative as it is required (for the current purposes of the exchange) and do not make your contribution more informative than is required; the Maxim of Relation: be relevant; and the Maxim of Manner: avoid obscurity of expression, avoid ambiguity, be brief ( avoid unnecessary prolixity), and be orderly.

Grice (1975,1989) further distinguishes between two classes of conversational implicatures: generalized conversational implicatures and particularized conversational implicatures. A particularized implicature is one which depends on particular features of the context, whereas a generalized implicature is one which does not depend on particular features of context, but instead typically associated with the proposition expressed. Under the heading of particularized conversational implicatures, Grice sheds light on that concept by giving a number of examples resulted from the flouting of the four conversation maxims: quality, quantity, relation, and manner. In discussing the flouting of the quality maxim, Grice works out a number of possible forms of implicature: irony, metaphor, meiosis (understatement), hyperbole (overstatement), social censure (censure means the act of expressing strong disapproval and criticism) and deliberate ambiguity. He also maintains that the flouting of the maxim of quantity can be either imparting information that a participant in conversation is reluctant to convey or write down, or can be in the form of tautology. Moreover, he argues that deliberate ambiguity is also the result of flouting of the maxim of relation. Additionally, when circumlocution is used, the maxim of manner is flouted. Instead of being brief, a speaker uses too many words to express an idea.

Nowadays, Grice's theory of how implicatures lain is at the center of research on the semanticspragmatics distinction which shapes much discussion of the relationship between language and mind. Grice brings implicature to the attention of philosophers and linguists, and his own account of the nature of implicature generation has provided a hugely influential framework for thinking about implicature in the light of semantic facts and facts regarding the nature of human interaction.

\subsection{Statement of the problem}

Through the researcher's teaching experience, it was noticed that the Yemeni EFL university learners encounter unsuccessful experience to communicate using English language. They are not sufficiently aware 
of the rules of the use of that language and that often words and expressions convey messages above and beyond their literal meanings. Therefore, it is not surprising that pragmatic errors are found as inevitable events in language learning process of their EFL communication. But, such failures which refer to the inability to recognize what is meant by what is said, may also result in too many communication failures that pose an obstacle to cross-cultural communication. Consequently, exacerbated inevitable problems may emerge from such misunderstandings. As a consequence of this, this problem requires urgent attention and effective solutions.

Thus, the reasons beyond such unsuccessful experience should be researched and uncovered to minimize and reduce such communication breakdown and help EFL university learners use English language appropriately. The intuitive difference between what is expressed literally in a sentence and what is merely suggested or hinted at by an utterance of the same string of words (implicature) should be understood by EFL university learners. Therefore, this current article is an attempt to identify the factors behind such communication breakdown in order to understand and to remedy them. The main concern of this study is to find out the factors beyond Yemeni EFL learners' misunderstandings of different English conversational implicatures.

\subsection{Objective of the study}

This study aims to:

Investigate reasons behind their mis/understanding of English conversational implicatures

\subsection{4 Significance of the study}

Hence, Yemeni EFL university learners need to use and perceive English language properly. This is expected to help them recognize various English utterances with regard to the situations they occurred in as people often use more than words when they communicate with each other. Therefore, the Yemeni EFL university learners' ability to identify the pragmatics of hints will be enhanced. It is hoped that the results of this study would make the future Yemeni EFL teachers, educators and students more attentive towards the importance of the pragmatic aspect of English conversational implicature.

Furthermore, hopefully the most important contribution that this study is expected to add in the field of teaching English language pragmatically to EFL university learners is that it identifies a problem, identifies the sources of such a problem, and suggests a practical teaching approach that would lead to solving that problem. This might open up new horizons for teachers, academics, students, curriculum designers and policymakers of how tackling such practical aspects help minimize the difficulties they face when teaching or learning different types of implicature, and when designing EFL curriculum respectively.

\section{Methodology}

This section describes the study design and methodology of this study. It highlights the study design, the population as well as sampling and data collection instruments and analysis. 


\subsection{Design}

This study is an empirical analytical-descriptive type with a test and an interview. It is an exploratory investigative research appropriate to identify the students' pragmatic awareness in interpreting different conversational implicatures. The study is both quantitative and qualitative since the students' wrong and right responses in mis/understanding each implicature in the study test are counted in numbers, whereas the participants' responses to the study interview questions are explained in words. Using an integration of quantitative and qualitative methods provides an expanded understanding of the research problem. Haq (2014) maintains that "there are greater benefits of using mixed methods than relying on either qualitative or quantitative methods alone" (p.18).

\subsection{Population and sampling}

The population of the study consisted of the fourth level students at the Department of English, Faculty of Education, Sana'a University, in the second semester of the academic year 2018/2019. They are three groups and their number is 163 students ( 151 female and 12 male). Randomly, 50\% of the study population was selected about (62 subjects) as the study sample. The purpose of deciding such percentage was to make the sample representative for the whole population. Randomisation was used to avoid bias in the selection of a sample and to represent the study population. According to Brink (1996) and Burns and Grove (2001), a random sampling ensures that all the participants have an equal chance to be selected and it avoids selection bias and thus typically reflects the characteristics of the population as a whole.

\subsection{Data collection instruments}

Data collection instruments of the study are represented by a test and an interview.

\subsubsection{Test}

The first instrument used in this study is an implicature test: the multiple-choice discourse completion test "MCDCT". To achieve the aim of the study, the sample of the study is subjected to this implicature test. All the test implicatures are taken from the study related literature including Grice (1989), Levinson (2000), Griffiths (2006), Hurford, Heasley, and Smith (2007), Sharpe (2007), and Huda (2013).

The scenarios of the test contain main categories of generalized and particularized conversational implicature in relation to the four maxims of cooperative principle: quality, quantity, relation and manner.

\subsubsection{Interview}

The second instrument used in the study is a semi structured interview which aims at investigating $10 \%$ of the population's (sixteen of the participants) problems and challenges, or ease regarding mis/understanding of the conversational implicatures in the test to find out the extent of difficulty/ ease in comprehending such implicatures. Patton (2002) points out that the principal advantage of using interviews as a tool to collect data is that the researcher can investigate things about the participants that $\mathrm{s} / \mathrm{he}$ cannot directly observe such as experiences, intentions, thoughts and feelings.

\subsubsection{Reliability and Validity}

The validity and reliability of the data collection instruments had been checked before the study was conducted . For the sake of validity, the initial version of the study test was shown to seven experts majoring in Pragmatics and Applied Linguistics to be checked. These seven experts were requested to determine the test validity in light of the following criteria: appropriateness of the test items in measuring the intended objectives and clarity of the language and instructions of the test. Experts' judgments helped to include plausible and consistent scenarios. 
Prior to conducting the study test, a pilot study was conducted on a group of $10 \%$ of the number of the population selected for the present study to examine the techniques needed for administering the study test. The other purpose for a pilot study was to investigate the possibilities of undertaking it in collecting the related data. As Polit, Beck and Hungler ( 2001) state that the purpose of the pilot study is to familiarize the researcher with the data collection and analysis procedures and to ensure that the instrument could be used properly.

\subsection{Data analysis}

The data in the present study collected by the test and interview was analyzed both quantitatively and qualitatively. After collecting the data from the study subjects to the study test, an analysis of the subjects' responses was conducted to identify, classify, and explain them. In order to answer the study question, the Statistical Package for Social Sciences (SPSS) version 25 was used to analyze the data obtained during the study. The two methods of analyses, frequency and difficulty coefficient $\rho$, were used to measure the students' pragmatic competence in comprehending conversational implicatures. Each of the study subjects obtained a score of 1 if the implicature's interpretation was selected correctly. If they failed to interpret it, they received a score of 0 .

The difficulty of a test item is understood by the proportion of the subjects who answer a test item correctly. If this proportion is equal or higher than 50\%, the implicature is considered to be easy for them. On the other hand, if it is less than $50 \%$, the implicature is considered to be difficult for them. To calculate the difficulty of an item, the number of subjects who answered it correctly is divided by the total number of the subjects who answered it (correctly and incorrectly) multiply by 100 . Usually this proportion is indicated by the letter $\rho$, which denotes the difficulty of the item (Crocker and Algina, 1986). It is calculated by the following formula:

$$
\rho \mathrm{i}=\frac{\mathrm{A}}{\mathrm{N}} * 100
$$

where:

$\rho i=$ Difficulty index of item $\mathrm{i}$

$A=$ Number of correct answers to item $i$

$\mathrm{N}=$ Number of correct answers plus number of incorrect answers to item $\mathrm{i}$

In the study test, each implicature type is presented by two scenarios to ensure that the subjects understand the different implicature types thoroughly. If both proportions of the same type of implicature are equal to $50 \%$ or higher than it, it will be clear that this type of implicature is easy for the subjects. Meanwhile, if these proportions are less than 50\%, this will denote that this kind of implicature is difficult for them. However, in case the proportions of the subjects in responding to the two test scenarios that involve the same type of implicature are different, the proportion of one of them, for example, indicates that it is easy for the subjects, whereas the proportion of its counterpart denotes that it is difficult for them. Here the frequency of the subjects' right choice across the two same type implicature test scenarios was compared with the frequency of the incorrect choice of the pair of them. In other words, making decision of the implicature type's ease or difficulty was based on the frequency of the right choice in both scenarios of the same type of implicature by every subject. If the frequency of the right answers selected by every subject were higher than the frequency of the incorrect answers, the implicature type is considered to be easy for the subjects; otherwise it would be difficult for them.

After the test had been administered, the semi structured interview was conducted to have a clear vision of the subjects' performance, and to find out the potential sources of pragmatic failure/success that Yemeni EFL university learners tend to produce. 


\section{Findings and Discussion}

This study aims to gain a wide understanding of the reasons behind misunderstanding and understanding English conversational implicatures by Yemeni EFL university learners. Therefore, this section discusses the factors that affect Yemeni EFL university learners' competence to comprehend English conversational implicatures regarding the study test and interview. First, the following subsection presents the findings of the ten Yes/No questions. Findings with regard to the study test and the other interview questions are also referred to in the later subsection.

\subsection{Getting information regarding how subjects obtain socio-cultural background of English}

Figures 1 to 4 below report the data on how the students gain the socio-cultural background of English.

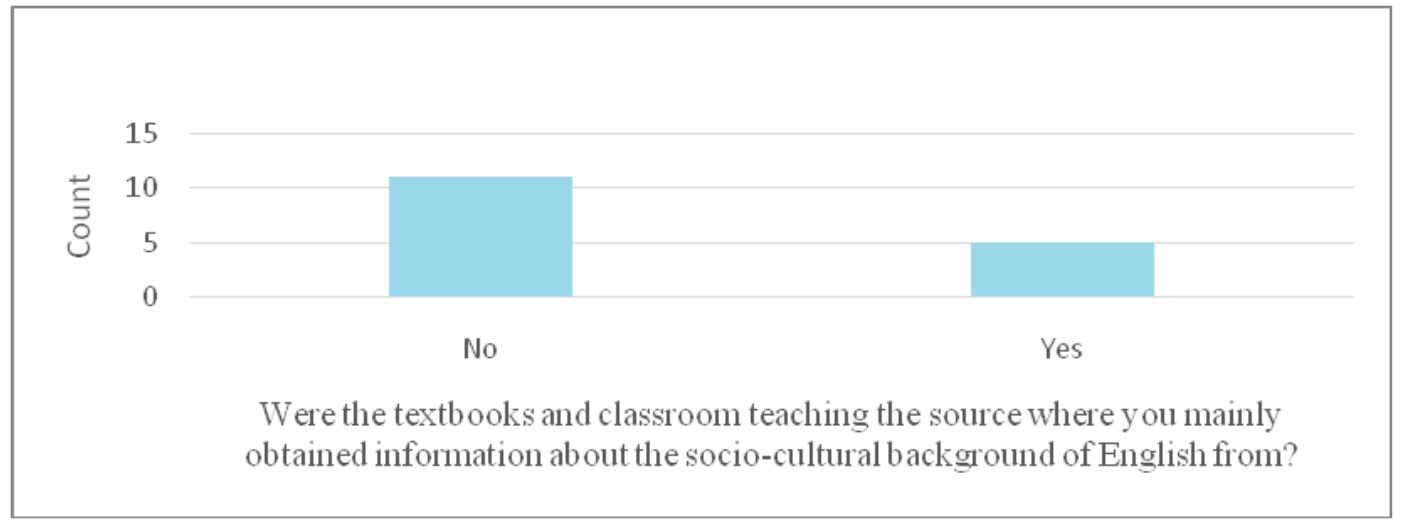

Figure 1. Were the textbooks and classroom teaching the source where you mainly obtained information about the socio-cultural background of English from?

It is apparent from Figure 1 that approximately two-thirds (more than ten) of those students questioned reported that the textbooks and classroom teaching were not the source where they mainly obtained information about the socio-cultural background of English from. The result suggests that they did not only get this kind of information from the textbooks and classroom teaching, but also that they got it from other different sources.

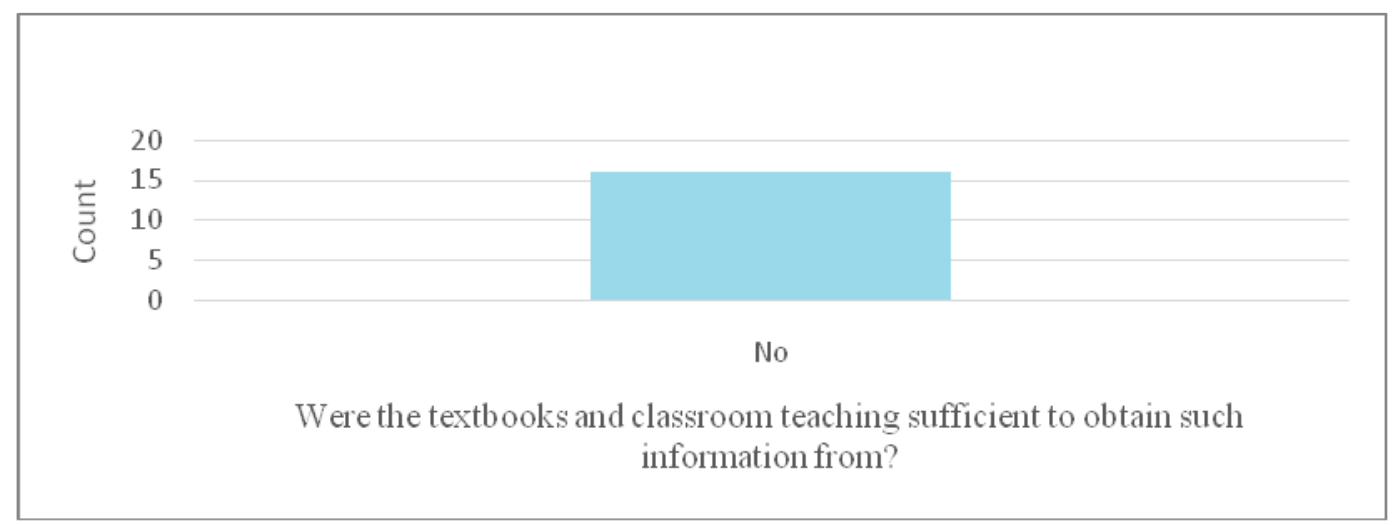

Figure 2. Were the textbooks and classroom teaching sufficient to obtain such information from?

We note from Figure 2 that all those interviewed reported that the textbooks and classroom teaching were not sufficient to have such amount of information from. It would seem to suggest that little information about socio-cultural background of English has been presented in the textbook and classroom teaching.

Figure 3 below shows that the majority of the respondents got the socio-cultural conventions of English speaking countries from other sources like English TV programs and serials. 


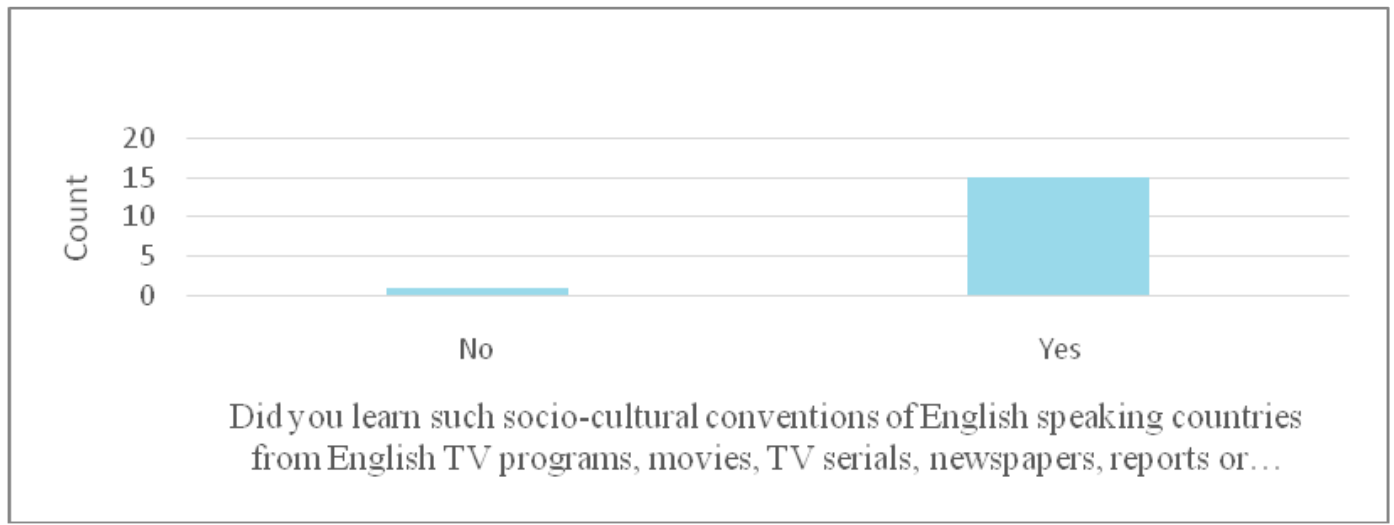

Figure 3. Did you learn such socio-cultural conventions of English speaking countries from English TV programs, movies, TV serials, newspapers, reports or magazines?

An interesting remark is that all interviewees said that English TV programs and serials were their main source of English socio-cultural conventions comparing with other sources that were mentioned in the question.

As can be seen in Figure 4 below none of the participants have communicated with foreigners using English to learn more about that language.

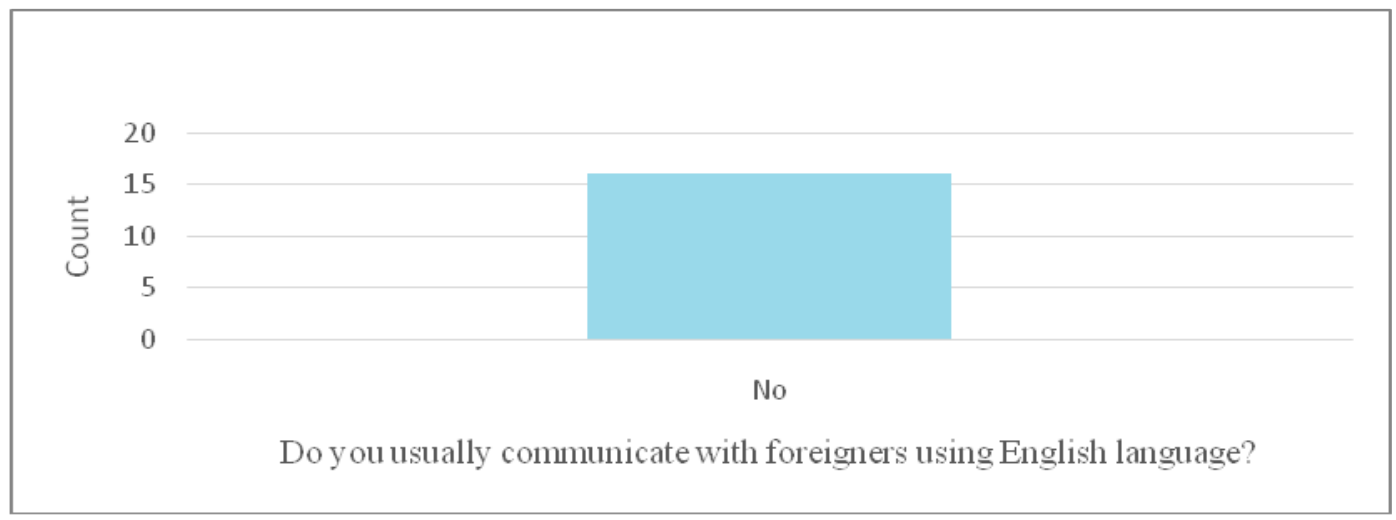

Figure 4. Do you usually communicate with foreigners using English language?

Because of that, all the interviewees are girls, and because Yemeni people are very conservative, no girls, are allowed to share information with outsiders or to talk to foreigners.

The results of the first four Yes/No questions suggest that the participants received little socio-cultural background throughout the textbooks and classroom teaching. That is, such resources are not enough to provide the respondents with necessary information about socio-cultural aspects of the English language. All the interviewees were not also satisfied with the amount of information they provided. They mainly got English socio-cultural conventions from English TV programs and serials. They also never have contact with foreigners to learn such information due to some socio-cultural restrictions. Turning now to the respondents' experience concerning reading or listening conversational implicatures and their feelings towards learning English and its culture. 


\subsection{Respondents' experience and attitudes towards English and its culture}

The other six Yes/No questions have been put forward to let the participants speak from their experience. Figures 5 to 10 present data about respondents' experience and how they got them and show respondents' attitudes with regard to English and its culture.

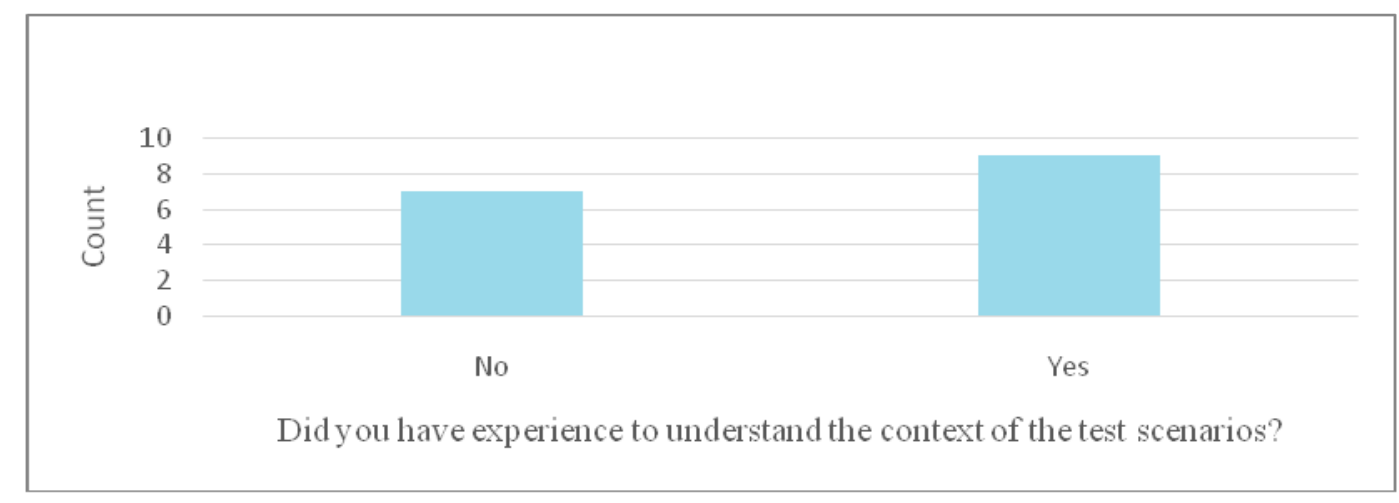

Figure 5. Did you have experience to understand the contexts of the test scenarios?

When the respondents were asked about whether they had experience to understand the contexts of the test scenarios or not. Over half of them reported that they had experience as presented in Figure 5. They either have read or listened to such situations before.

All those who responded reported that there were some of the test scenarios' contexts have their equivalents in Arabic as shown in Figure 6 below.

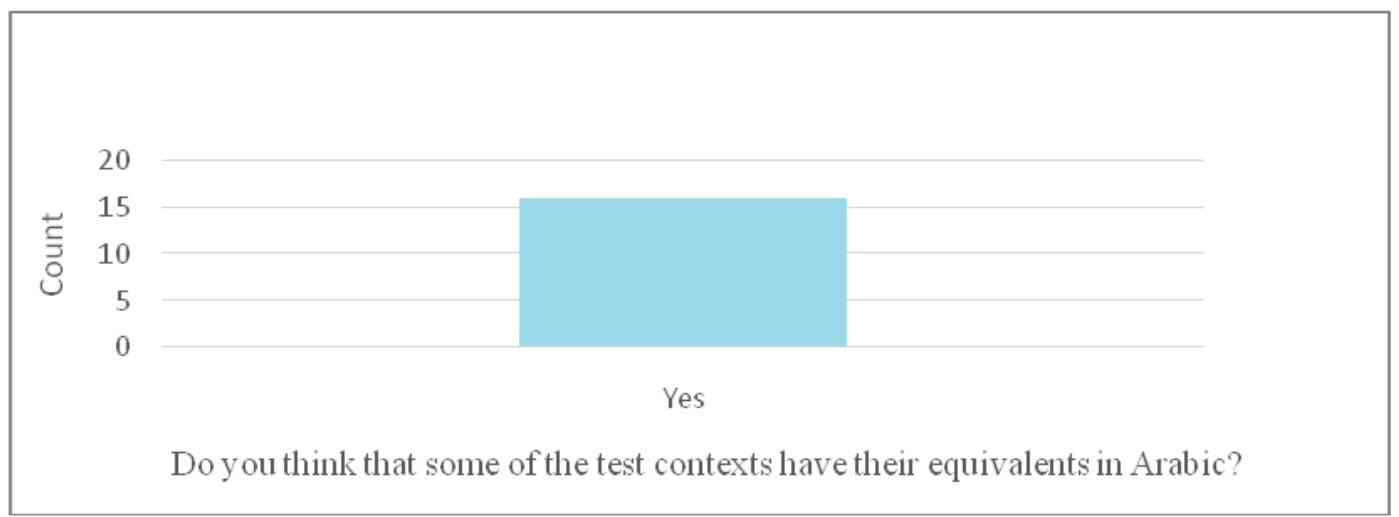

Figure 6. Do you think that some of these contexts have their equivalents in Arabic?

As all languages have pragmatic systems, Arabic and English still show some similarities in generating some implicatures. There are some underlying similarities between the two languages which are clear to the respondents. In this regard, Shehab (2004) states that the literal translation works in conveying the meaning in rendering some Arabic implicatures into English. And this has been obvious in the translating of some Arabic tautological and ironical utterances. This is uniquely relevant evidence of likeness of some aspects of both languages. Similarly, most of the present study subjects have successfully interpreted tautological and ironical implicatures.

Despite of language universality, any language has its own sense, taste, construction, expressions explicitly or implicitly. In response to the following question, all the participants also agreed that the nature of some of these contexts is somewhat different from Arabic as it can be seen in Figure 7 below. 


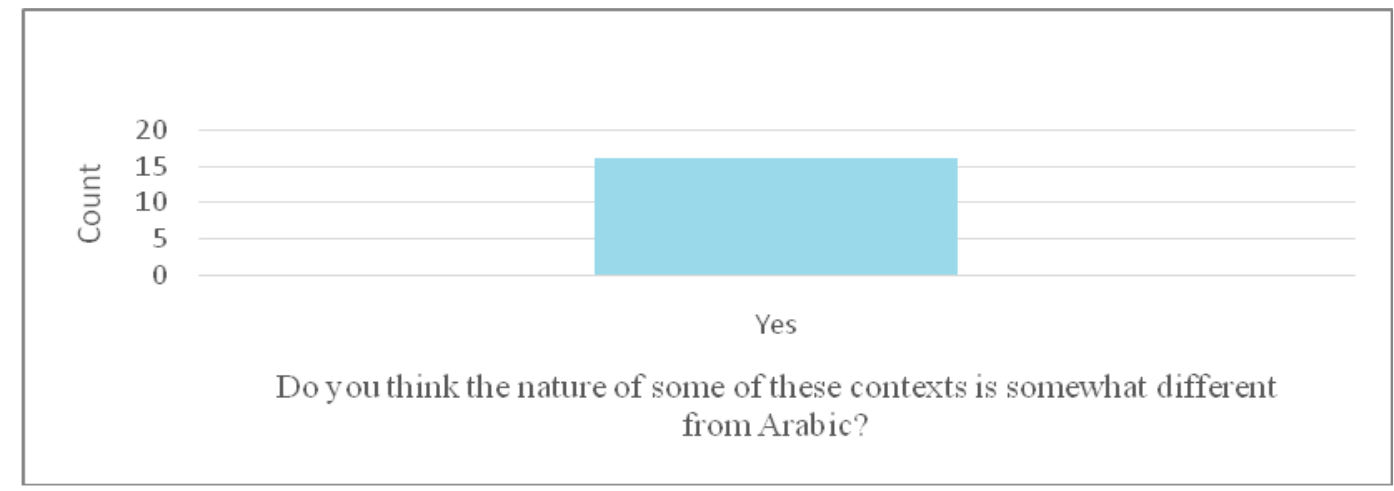

Figure 7. Do you think the nature of some of these contexts is somewhat different from Arabic?

This is because English and Arabic are two different language systems and derived from different cultures. These differences have a deep impact in comprehending English conversational implicature (Baker, 2011).

To know more about the study participants' experience, the question "did you study English in institutions for teaching English before joining the Department of English at the Faculty of Education?" is asked. As institutions for teaching English in Yemen are renowned for providing their students with various cues of how the English language used by its native speakers. They provide those learners, who are rarely exposed to the target language culture, with practical English situations/utterances for daily life assisting them to avoid pragmatic failure in some test contexts. Figure 8 below presents that approximately two thirds of the respondents have studied in these institutions before joining the Department of English at the Faculty of Education. This may help them to interpret some of the test implicatures.

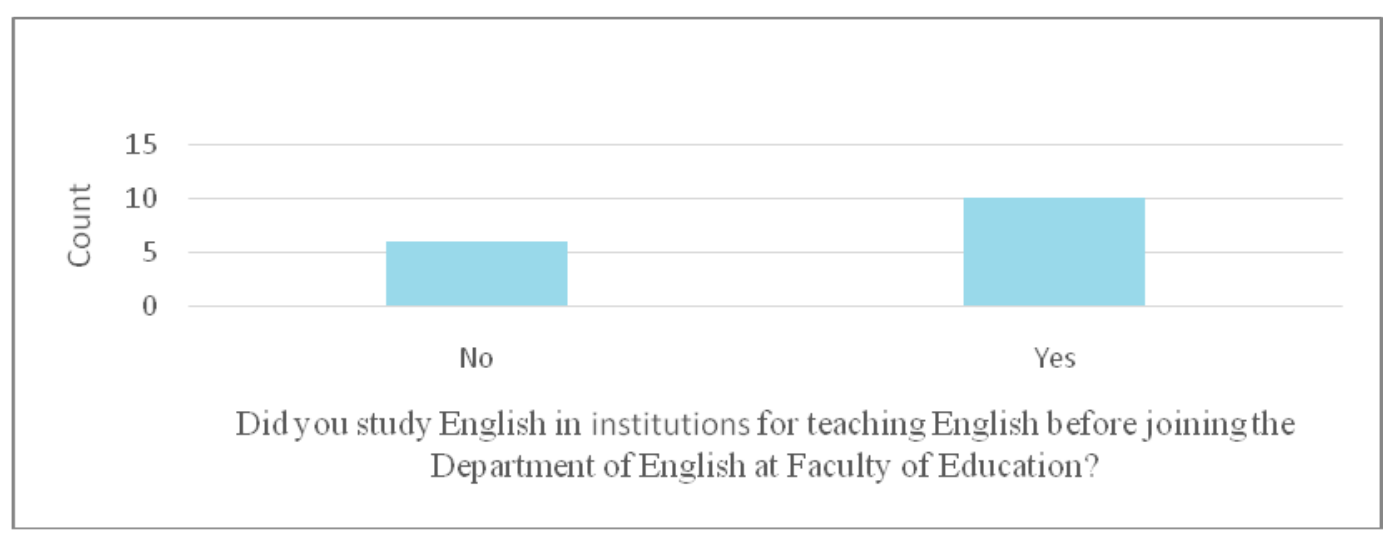

Figure 8. Did you study English in institutions for teaching English before joining the Department of English at Faculty of Education?

Furthermore, in response to the question: do you teach English in any of the institutions for teaching English now?, almost all of those questioned mentioned that they do not teach in such institutes now as it is shown in Figure 9 below. 


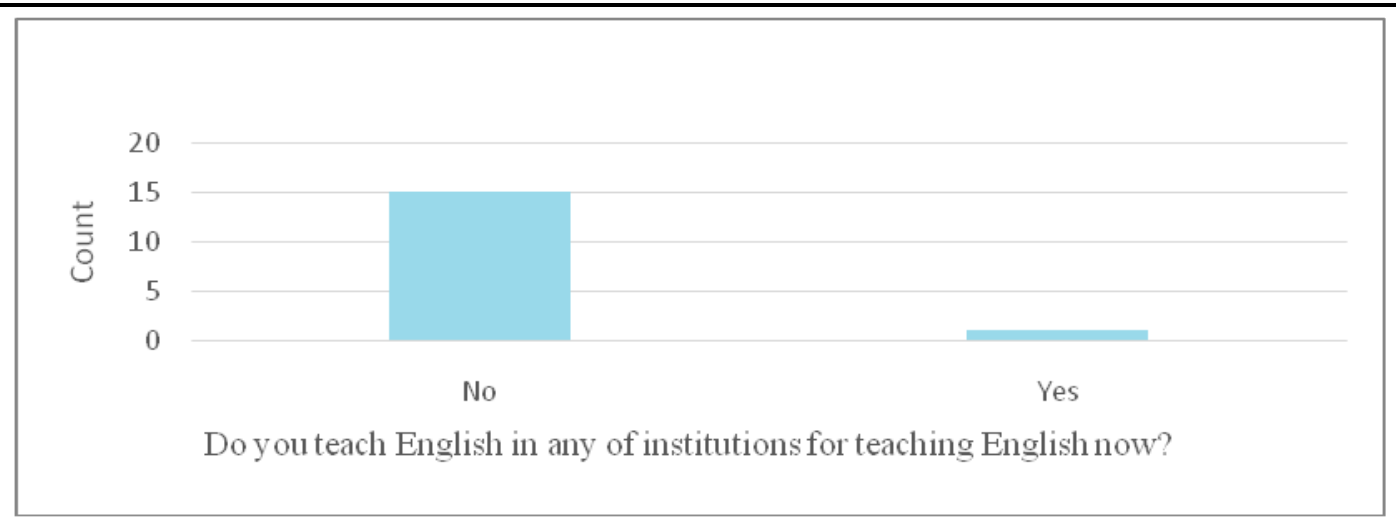

Figure 9. Do you teach English in any of the institutions for teaching English now?

We observe from Figure 10 below that many participants do not feel lack of interest from their part in learning English or its culture. But, some participants (7 participants) still feel of that. They have no desire for learning English and they are more than a third of the interviewees.

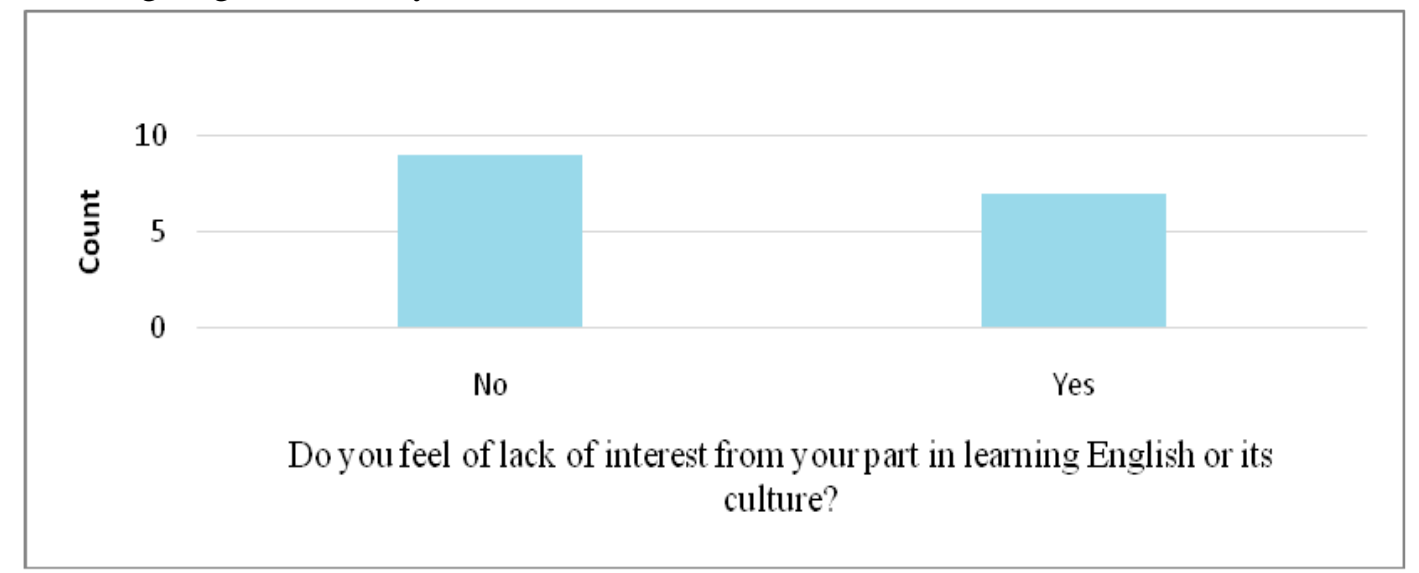

Figure 10. Do you feel lack of interest from your part in learning English or its culture?

This demonstrates that the lack of interest in learning English and its culture from these students partly constituted a hindrance of learning English in general and learning its socio-cultural aspects in particular. As these aspects are considered to be the cornerstones in getting English pragmatic competence, some participants said that going to the Faculty of Education results not from free choice, but from coercion. Their parents gave them no choice in making decision which faculty they would join. As a consequence, they do not feel satisfied because they have not got what they want.

\subsection{Findings regarding study test and interview}

There are some other factors that influenced the study subjects to misunderstand or understand conversational implicatures according to the study test and interview questions.

The study test findings appear to be supported by the interview findings. In the interview, for example, the context and indirectness were revealed as factors of miscomprehending conversational implicatures by many respondents. According to the study test and interview findings, there are several reasons of mis/understanding conversational implicatures which are discussed as follows:

1. The context and indirectness which is used as long as the conversational implicatures are concerned, were an issue of not perceiving some implicatures of the study test. This is a challenging task for foreign learners because they have to recognize the relationship between the utterance meaning and the intended meaning before making inferences about the speaker's meaning. Without knowing the context, people often make misunderstandings. The test indirect criticism, disapproval, and assertion implicatures are good examples of the context difficulty. 
Indirectness is also problematic for foreign language learners. This makes ambiguity and, therefore, requires people to make guesses about the speaker's intentions. It is considered to be a feature of conversational implicatures. Take, for instance, the test deliberate ambiguity, indirect refusal, and indirect criticism implicatures.

2. Two more reasons of misinterpreting some conversational implicatures are differences in English and Arabic cultures and English and Arabic semantic misalignment interference. Culture difficulty was shown by the test deliberate ambiguity and indirect refusal implicatures. Using the sociolinguistic rules of one's native language to communicate in the target language, for example, is a problem resulted from contrasted cultures of different languages as occurred in misinterpreting the study test indirect requests. Also, English and Arabic semantic misalignment interference leads to misunderstanding some of the test implicatures such as the test overstatement implicautre

3. In addition to the differences of cultural background, insensitivity to what is conveyed through the particular styles of a language utterance can in some cases become an obstacle to correctly understanding the conversational implicatures. For instance, the ways of generating some conversational implicatures in English and Arabic are different such as assertions.

4. Negative transfer of language features and cultures from Yemeni Arabic also affects the subjects' understanding of conversational implicatures. This was true of the implicature included in the test assertion situation of a mother is taking to her child, and also of the implicature included in the test indirect request situation of the conversation of the two companions, Tim and Kate.

5. The limited experience that the subjects had about conversational implicatures and inadequate amount of cultural information and pragmatic knowledge about the English language provided by the university textbooks and other teaching materials, are other factors in not comprehending some of the test conversational implicatures. As pragmatic knowledge will help learners to understand why native speakers use certain structures in different speech situations. Students in the Faculty of Education were involved in activities that concentrate on how to make learners memorize the required information, as one of the study respondents reported. Authentic materials were rarely or never brought into the classroom which would certainly expand the students' exposure to various kinds of pragmatic input in English. Also, the limited amount of cultural and pragmatic information about English provided in the university textbooks caused miscomprehension of conversational implicatures. This reduces the stock of the students' skills and experience to expose to how English is used naturally or how to be used in daily life. Consequently, this may make them fail to recognize a speaker's communicative intention in many situations of the study test.

6. Partial understanding of some test situational contexts and narrow range of vocabulary that the subjects had, further set up barriers to their success in interpreting conversational implicatures. Ignoring some phrases (hedges) and misunderstanding the context as a whole also affect the subjects' interpretation of some test implicatures such as the test of disapproval implicature. In their study, Ishihara and Cohen (2010) maintain that the fact that the limited ability and knowledge of vocabulary of the second language affects the difficulty of second language learners to use pragmatic features of English.

7. Yemeni EFL university students' lack of motivation undermines to some extent their willingness to learn English, in general, and its culture, in particular.

8. The respondents contended that unfamiliarity is also a reason for misinterpreting some of the test implicatures. However, familiarity factor plays a role in subjects' success in interpreting some of the test conversational implicatures. The vast majority of subjects, for example, comprehended some of the test implicatures which have equivalents in the their first language like tautology and rhetorical question implicatures. The respondents provided some examples of the comparable implicatures presented in the Yemeni Arabic language and culture. Moreover, the implicatures that the subjects have listened to or read before were also interpreted successfully. As some respondents reported that they had experience to understand the contexts of the test or not, over 
half reported that they had experience, and that approximately two thirds of the respondents reported that they studied in institutions of teaching English before joining the Department of English at the Faculty of Education. This may help them to interpret some of the test implicatures.

\section{Conclusion}

Levinson (1983) highlights that implicature is an example of the most typical phenomenon of pragmatic usage. It is considered a strategy frequently used in communication.

This study suggests that little attempt is made in the EFL classroom to make learners, instructors, and curriculum designers aware of implicature as a tool of communication and to enhance them to practice, teach and incorporate it when using, and teaching English or when planning English syllabus for students at university. It has shown that the most common factors affecting Yemeni EFL university learners' competence to comprehend English conversational implicatures regarding the study test and interview which are the following:

1. Socio-cultural difference: This study has shown that socio-cultural differences between Arabic and English are the main source of failure in understanding English conversational implicatures. The context, which is "any background knowledge assumed to be shared by $\mathrm{S}$ [a speaker] and $\mathrm{H}$ [a hearer] and which contributes to H's interpretation of what $\mathrm{S}$ means by a given utterance" Leech (1983, p. 13), plays a crucial role in determining what someone means by what s/he says. English and Yemeni Arabic semantic misalignment interference, for example, is considered to be fundamental cultural pragmatic failure. Moreover, the different socio-cultural ways of how to discipline children, for instance, misled the study subjects to choose the correct answer in the test assertion scenario. In the test indirect request scenario of misunderstanding Kate's intention as a reproving, is further concerned with socio-cultural differences.

2. Indirectness: This plays a central role in miscomprehending English implicatures by Yemeni EFL university learners as the indirect way of saying them hinders their correct interpretation. Many interviewees informed the researcher that in many test scenarios, they could not understand what speakers were saying as they did not express their intentions straightforwardly.

3. Negative transfer: Yemeni EFL university students' pragmatic knowledge in their mother tongue has a significant impact on their understanding of pragmatic performance in English. Negative transfer occurs when the learners subconsciously apply the conventions of their mother tongue to the target language. The use of some conventions or the use of physical carryover of the study subjects' native language, Yemeni Arabic, was a result of its influence. These certain conventions negatively affect the subjects' performance and lead to misunderstanding of some English implicatures including the test assertion and indirect request.

4. Teaching-induced shortcomings: The lack of interaction and exposure to the target language in EFL context poses a challenge as the classroom becomes the main place for learners to acquire and develop their competence including pragmatic competence. However, the English teaching system at the Faculty of Education, Sana'a University and in most Yemeni universities is examinationoriented, which means that the goal of the English teaching is to prepare students to accomplish good scores on a wide range of test papers. As a result, knowledge conveyed in the classroom is mainly about vocabulary and grammar (linguistic competence). Though it is advocated that the four main skills of the English language should be developed equally, the skills that are actually 
developed are only those needed in examinations rather than for practical use.

What is more, as traditional methods of teaching and learning are tended to be followed in the Yemeni EFL classrooms, learners, who have been educated through these methods of teaching, have difficulty to interpret socio-cultural aspects of conversational implicatures. All the study interviewees were not satisfied to the amount of the socio-cultural background of English that classroom teaching and the college textbooks provide. The study subjects' overall performance in the study test further highlighted the little experience they had with socio-cultural aspects of English.

Limited pragmatic input and knowledge in many cases also impede the Yemeni EFL university learners to comprehend one of the important components of pragmatics, conversational implicature. Yemeni EFL university students only learn what was modeled in classroom and what they memorized. As a result, the participants of the study seem to complain of forgetting of vocabulary during their study of different courses at the college. That is, the learning process of English is restricted to the classroom.

On the other hand, the present study has also shown that Yemeni EFL university learners successfully interpreted some of the test implicatures, since these implicatures are similar to those in their native language (Yemeni Arabic), experienced by them, familiar to them, or formulaic. These implicatures are stating, tautology, rhetorical question, understatement, indirect refusal, and indirect request. As these implicatures were close to the ones the study subjects used in their daily conversations, they were easily interpreted by them. Al-Duais (2010) and Al-Qaderi (2015) studies' results showed that it is possible to apply Gricean Theory of Conversational Implicature to Arabic language, particularly the Yemeni dialect. The students in the current study further gained some pragmatic cues and conventions that assisted in comprehending some of the test implicatures from different sources. They got a few of them inside the college, however, they acquired a lot of them from sources outside the college such as English TV programmes and serials, and institutes of teaching English, which they have studied at before joining the college. Another point is that the formulaic nature of certain implicatures did not constitute any obstacle to be understood by many Yemeni EFL university students. In this regard, Bouton (1999) states that nonformulaic implicatures lack an overall system and consequently do not have a pattern to be taught and learned systematically.

Based on the study results, EFL university learners, in general, and Yemeni Arab EFL university learners, in particular, are recommended to be taught and given enough practice in how to understand and produce English conversational implicatures. The topic of conversational implicature is highly recommended to be included as one of the teaching components in one of the EFL university courses, in the upper levels in particular. In this course framework, English pragmatic information and tasks should be employed to make learners consciously aware of the difference or similarity between the native and target language norms, in general and the types of conversational implicature and its uses, in particular. Furthermore, pragmatic issues should be emphasized in EFL classroom teaching methodology; communicative language teaching should be involved in teaching pragmatics.

In further future studies investigating conversational implicatures, it is suggested by the study that research might be extended beyond just understanding English conversational implicatures. It would be preferred if expanded to include studies on writing English conversational implicatures or comparing English conversational implicatures with Yemeni Arabic ones to gain a deeper understanding of the complex components of communication interaction. 


\section{References}

[1] Al-Duais, A. (2010). Conversational implicature (flouting the maxims): Applying conversational maxims on examples taken from non-standard Arabic language, Yemeni dialect, an idiolect spoken at IBB City. Paper presented at Ministry of Higher Education conference for Higher Studies students in Saudi Arabia (2nd conference, 2010). King Saud University.

[2] Al-Eryani, A. (2008). Interlanguage pragmatics of the Yemeni undergraduate learners of English: Problems and remedies. A study in EFL. Unpublished Ph.D. thesis. Faculty of Languages, Panjab University, Chandigarh.

[3] Al-Ghbari, D. (2016). Integrating pragmatic competence in teaching English to the students of Medicine at Taiz University. Unpublished Ph.D. thesis. Université De Strasbourg.

[4] Al-Qaderi, I. (2015). Conversational Implicature in Arabic: A pragmatic analysis of applying flouting the maxims to the Yemeni dialect. International Journal of Linguistics, 7, (6), 53-68.

[5] Al-Sanhani, H. (2007). The effect of instruction on development the pragmatic competence of EFL Yemeni learners. Unpublished M.A. thesis. Faculty of Education, Sana'a University.

[6] Amaya, L. (2008). Teaching culture: Is it possible to avoid pragmatic failure? Revista Alicantina de Estudios Ingleses, 21, 11-24.

[7] Austin, J. (1962). How to do things with words. London: Oxford University Press.

[8] Baker, M. (2011). In other words: A Coursebook on Translation.2nd Edition. London: Routledge.

[9] Bouton, L. F. (1999). Developing nonnative speaker skills in interpreting conversational implicatures in English: Explicit teaching can ease the process. In H. Eli (Ed.), Culture in second language teaching and learning (pp. 47-70). Cambridge: Cambridge University Press.

[10] Brink, H. (1996). Fundamentals of research methodology for health care professional. Kenwyn: Juta.

[11] Burns, N. \& Grove, S. (2001). The practice of nursing research: Conduct, critique and utilization. Philadelphia, Pennsylvania: W.B. Saunders.

[12] Crocker, L. \& Algina, J. (1986). Introduction to Classical and Modern test Theory. New York: Holt, Rinehart and Winston.

[13] Ghaleb, A. (2003). A Pragmatic analysis of speech acts as produced by native speakers of Arabic in English. Unpublished Ph.D. thesis. Department of Linguistics, Aligarh Muslim University, India.

[14] Gibbs, R. (1983). Do people always process the literal meanings of indirect requests? Journal of Experimental Psychology: Learning, Memory, and Cognition, 9, 524-533.

[15] Grice, H. P. (1975). Logic and conversation. In P. Cole and J. Morgan (Eds.), Syntax and Semantics, (vol. 3 pp. 41-58).New York: Academic Press.

[16] (1989). Studies in the way of words. Harvard University Press.

[17] Griffiths, P.(2006). An introduction to English semantics and pragmatics. Edinburgh. Chippenham, Wilts.

[18] Haq, M. (2014). A comparative analysis of qualitative and quantitative research methods and a justification for use of mixed methods in social research. Paper presented at Annual PhD Conference, June 2014. University of Bradford Business School of Management.

[19] Huda, M. (2013). Conversational implicature found in dialogue of Euro Trip Movie. Unpublished M.A.

[20] Hurford, J., Heasley, B. \& Smith, M. (2007). Semantics: A Coursebook. New York. Cambridge University Press.

[21] Ishihara, N. \& Cohen, A. D. (2010). Teaching and learning pragmatics: Where Language and Culture Meet. New York: Routledge.

[22] Leech, G. (1983). Principles of pragmatics. London: Longman.

[23] Levinson, S. (1983). Pragmatics. Cambridge: Cambridge University Press.

[24] (2000) . Presumptive Meanings: The theory of generalized conversational implicature. Cambridge, MA: MIT Press.

[25] Mey, J. (2002). To Grice or not to Grice. Journal of Pragmatics, 34 (8), 911-911.

[26] Patton, M. Q. (2002). Qualitative research and evaluation methods (3rd ed.). Thousand Oaks, CA: Sage Publications. 
[27] Polit, D. Beck, C. \& Hungler, B. (2001). Essential of nursing research: Methods, appraisals, and utilization. Philadelphia: Lippincott.

[28] Recanati, F. (2006). Pragmatics and semantics. In L. Horn \& G. Ward (Eds.), Handbook of Pragmatics (pp. 442-462).Oxford. Blackwell.

[29] Searle, J. (1979). Expression and meaning: Studies in the theory of speech acts. Cambridge: Cambridge University Press.

[30] Sharpe, P. (2007). Practice exercises for the TOEFL: Test of English as a foreign language. 6th Edition. New York. Barron's Educational Series, Inc.

[31] Shehab, E. (2004). The translatability of utterances containing implicatures from Arabic into English. An-Najah Univ. J. Res. (H. Sc.), 18(2), 691- 709. 